\title{
A HIGH DEGREE OF MYOPIA
}

BY

\author{
M. W. B. Oliver, M.A., M.B., B.C.Camb., F.R.C.S.Eng. \\ LONDON.
}

THE patient, J. H., is aged 35 years. He has served for two years in the Army in a labour battalion, and for about one year of this time he was in France.

In the right eye the retinoscopy is $-60 \mathrm{D}$., and in the left $-24 \mathrm{D}$. His vision in each eye without glasses is less than $1 / 60$ and with the full correction in the right is $3 / 60$, and in the left $6 / 60$.

The fundus in both eyes is normal except that in each eye there is a very small myopic crescent. The absence of any marked fundus changes and the fact that the eyes are not abnormally prominent seems to show that this is probably a congenital condition, the eyes being abnormally large and the orbits correspondingly increased in size.

It has not yet been possible to have an $X$ ray taken of the orbits as the man has considerable difficulty in attending hospital.

\section{AN EYELASH IN THE BULBAR SUBCONJUNCTIVAL TISSUE}

\author{
BY \\ J. Hamilton McIlroy, M.B., D.Sc. \\ ASSISTANT OPHTHALMOLOGIST, 3RD SCOTTISH GENERAL HOSPITAL.
}

THE following condition being of rather unusual occurrence, appears to be worthy of a brief note.

Private T. was sent on account of defective vision and discomfort in the right eye.

He stated that about five months previously he was injured in the right ${ }^{\circ}$ arm and eye by the explosion of a shell. He was treated in a base hospital, mainly on account of the injury to his arm, the eye condition demanding little attention at the time. Although he did not complain of much amiss with his eye, he has felt, since the injury, that there was something wrong, and he ultimately reported sick, and was sent to this hospital.

On examination the condition was as follows: R.V. 6/12; L.V. $6 / 6$.

The right eye showed little or no sign of lesion on ordinary inspection, but on careful examination with the corneal loupe, a small whitish object was seen at the outer part of the limbus, and was taken to be a "foreign body" lying superficial to the limbus. There was a slight degree of local inflammation involving the cornea 